\title{
Nitric oxide inhalation as an interventional rescue therapy for COVID-19-induced acute respiratory distress syndrome
}

\author{
Jun Kobayashi* and Isamu Murata
}

\begin{abstract}
COVID-19 is an emerging disease of public health concern. While there is no specific recommended treatment for COVID-19, nitric oxide has the potential to be of therapeutic value for managing acute respiratory distress syndrome in patients with COVID-19. However, inhaled nitric oxide has not yet been formally evaluated. Given the extent of the COVID-19 pandemic, and the large numbers of hospitalized patients requiring respiratory support, clinical use of inhaled nitric oxide may become an alternate rescue therapy before extracorporeal membrane oxygenation for the management of acute respiratory distress syndrome in patients with COVID-19.
\end{abstract}

Novel coronavirus disease 2019 (COVID-19) is an emerging disease of public health concern, and the current pandemic is having a major global impact. Increasing attention is being focused on the development of therapeutic strategies against this disease. We read, with great interest, the article by $\mathrm{Li}$ et al. "Therapeutic strategies for critically ill patients with COVID-19" published in this journal [1]. While there is no specific recommended antiviral treatment, and vaccines have yet to be developed, the authors provided a powerful pharmacological strategy for the treatment of critically ill patients with COVID-19 acute respiratory distress syndrome (ARDS). In this review article, the drug applications for COVID-19 are well described according to disease severity; however, nitric oxide (NO) inhalation therapy, which is not described in this review, may be included in the strategy as a promising therapeutic candidate. In 2004, during the severe acute respiratory syndrome coronavirus (SARS-CoV) outbreak, a pilot study showed that lowdose inhaled NO ( $\max 30 \mathrm{ppm})$ could shorten the time of ventilatory support for patients infected with SARS$\mathrm{CoV}$ [2]. Although epidemiological evidence supporting

\footnotetext{
*Correspondence: junkoba@josai.ac.jp

Faculty of Pharmacy \& Pharmaceutical Science, Josai University, 1-1 Keyakidai, Sakado, Saitama 350-0295, Japan
}

the use of inhaled NO in treating COVID-19 has not yet been identified, similar therapeutic effects of $\mathrm{NO}$ can be expected for patients with COVID-19 due to the genetic similarities between the two viruses [3]. Based on this experience, clinical trials have begun in several medical institutes in the United States, and now a phase 2 clinical trial of inhaled NO is being conducted for mechanically ventilated patients with COVID-19 ARDS to confirm whether NO inhalation will become an interventional therapy to rescue patients with this disease [4].

The inflammatory cytokine storm induced by virus infection is closely related to the development and progression of ARDS. Given the common pathological process leading to virus-induced ARDS [3], previous experience suggests that inhaled NO may be useful for managing COVID-19 ARDS. Previously published in vitro studies indicated that NO possessed inhibitory effects on SARS-CoV replication. Moreover, growing evidence has shown that inhaled NO can reduce inflammatory cell-mediated lung injury by inhibiting neutrophil activation and subsequent pro-inflammatory cytokine release. Due to its potent and selective pulmonary vasodilation, inhaled NO can lower pulmonary vascular resistance and decrease edema in the alveolar spaces, which enhances ventilation/perfusion matching. In addition, recent evidence also suggests that inhaled NO could 
have a wide range of systemic effects via cGMP-dependent and -independent mechanisms leading to a decrease in vascular tone, and a reduced risk of thrombosis and leukocyte adhesion to pulmonary and systemic vascular endothelium [5]. Because NO acts as a pro-inflammatory and an anti-inflammatory agent, depending on the amount of NO generation and its source, early and timely initiation of inhaled NO therapy may prevent cytokine storms following abnormal vascular endothelium/leukocyte interactions.

In severe COVID-19 ARDS with hypoxemia despite optimizing ventilation and other rescue strategies, extracorporeal membrane oxygenation (ECMO) is the final therapeutic option [1]. However, given the high running cost, limited number of devices, and the skilled medical staff required to perform ECMO, inhaled NO, which is relatively of low cost and readily available, may be a promising interventional therapy for patients with severe COVID-19 ARDS. Because inhaled NO has been extensively applied to treat pulmonary hypertension, ARDS, and other respiratory diseases with a relatively good safety profile, we advocate for a clinical trial exploring the use of inhaled NO for the management of COVID-19 ARDS to be conducted as a matter of urgency.

\section{Abbreviations}

COVID-19: Coronavirus disease 2019; ARDS: Acute respiratory distress syndrome; NO: Nitric oxide; SARS-CoV: Severe acute respiratory syndrome coronavirus; ECMO: Extracorporeal membrane oxygenation.

\section{Acknowledgements}

None.

\section{Authors' contributions}

Dr. JK devised the concept and wrote the manuscript draft, and Dr. IM helped with editing. Both authors read and approved the final manuscript.
Funding

No funding was used for this report.

Availability of data and materials

Not applicable.

Ethics approval and consent to participate

Not applicable.

\section{Consent for publication}

Not applicable.

\section{Competing interests}

The authors declare that they have no competing interests.

Received: 29 April 2020 Accepted: 14 May 2020

Published online: 20 May 2020

\section{References}

1. Li L, Li R, Wu Z, Yang X, Zhao M, Liu J, et al. Therapeutic strategies for critically ill patients with COVID-19. Ann Intensive Care. 2020;10:45. https:// doi.org/10.1186/s13613-020-00661-z.

2. Chen L, Liu P, Gao H, Sun B, Chao D, Wang F, et al. Inhalation of nitric oxide in the treatment of severe acute respiratory syndrome: a rescue trial in Beijing. Clin Infect Dis. 2004;39(10):1531-5.

3. Nicholls JM, Poon LLM, Lee KC, Ng WF, Lai ST, Leung CY, et al. Lung pathology of fetal severe acute respiratory syndrome. Lancet. 2003;361:1773-8.

4. Lei C, Su B, Dong H, Bellavia A, Di Fenza R, Fakhr BS, et al. Protocol of a randomized controlled trial testing inhaled nitric oxide in mechanically ventilated patients with severe acute respiratory syndrome in COVID-19 (SARS-CoV-2). medRxiv. 2020. https://doi.org/10.1101/2020.03.09.20033 530 .

5. McMahon TJ, Doctor A. Extrapulmonary effects of inhaled nitric oxide: role of reversible S-nitrosylation of erythrocytic hemoglobin. Proc Am Thorac Soc. 2006;3(2):153-60.

\section{Publisher's Note}

Springer Nature remains neutral with regard to jurisdictional claims in published maps and institutional affiliations.

\section{Submit your manuscript to a SpringerOpen ${ }^{\odot}$ journal and benefit from:}

- Convenient online submission

- Rigorous peer review

- Open access: articles freely available online

- High visibility within the field

- Retaining the copyright to your article

Submit your next manuscript at springeropen.com 